\title{
The Design of Control System for Water Dispenser Water Content Based on MCU
}

\author{
Shiyong Zheng ${ }^{1}$, Zhao $\mathrm{Li}^{2}$, a, Biqing $\mathrm{Li}^{3, \mathrm{~b}}$ \\ ${ }^{1}$ College of Computer Science and Information Engineering, Hezhou University, Hezhou \\ Guangxi 542899, China; \\ ${ }^{2}$ Management Engineering Department, Guangxi vocational and technical college of \\ communications, Liuzhou Guangxi 530000, China; \\ ${ }^{3}$ College of Mechanical and Electronic Engineering, Hezhou University, Hezhou Guangxi 542899, \\ China. \\ ajanliful@163.com, b229292710@qq.com
}

Keywords: AT89S52 MCU; LCD; temperature probe ultrasonic module

\begin{abstract}
This page proposed a Water dispenser water temperature and water yield control system which used MCU AT89S52 as the core, it can be achieved heating water and monitoring water levels. To preset temperature through the input module, to detect water temperature by waterproof model DS18b20 temperature sensor and displays the real-time temperature of drinking water by using 1602 LCD screen. Compared with the preset temperature real-time temperature, heating water if the real-time temperature is lower than the preset temperature, otherwise stop heating. The water level can be positioned though the ultrasonic module, can be sounded the alarm when the liquid level height below the warning line. The system has very high use value with the advantages of simple design.
\end{abstract}

\section{Introduction}

The application of single chip microcomputer (SCM) in electronic products is becoming increasingly wider and deeper. Temperature measurement and control are also applied in many electronics. This design mainly aims to design a new intelligent control system which has the functions of temperature measurement, temperament control, and liquid level alarm.

\section{Design Idea and Scheme}

The mainframe unit, consisting of AT89S52 SCM and relevant memorizer, is the core of design. The name of key component and the main functions of the key parts in the circuits are as follows:

(1)AT89S52: it refers to the control of the collection procedure, collection mode and alarm process of monitoring system data; it is also the core processor of the whole system. At first, SCM compares the on-the-spot temperature measured by the sensor and the preset temperature. Providing that the on-the-spot temperature is greater or less than the preset temperature, the signal should be output to control the work of the heater, so as to control the temperature.(2Liquid crystal display LCD1602:it is used the display the current temperature, the set temperature, and the height of water level.(3)DS18B20:singlet line digital temperature sensor can be directly transformed into serial digital signal, so as to be processed by SCM.(4)Buzzer: it is used to point out the various states of the drinking fountains of users.(5)Key: modules are input to control SCM, in order to complete various kinds of functions.

\section{Design of System Hardware}

\subsection{Crystal Oscillation Circuit}

All SCM systems have crystal oscillators. Crystal oscillator is very effective in SCM system. It combines the internal circuit of SCM, generating the necessary clock frequency of SCM. The 
execution of all instructions of SCM is based on the basis. The higher the clock frequency offered by the crystal oscillator is, the faster the operating speed of SCM is. Crystal oscillator operates in the resonance state with a kind of crystal which can transform electric energy and mechanical energy mutually.

\subsection{Reset Circuit}

AT89C52SCM usually adopts power-on automatic reset and button reset. This design selects button reset circuit. A normally open button is required to be parallelly connected power-on reset circuit. When the button is pressed, the RST pin end can be in high level, to rest SCM. The circuit diagram is as shown in Figure 1.

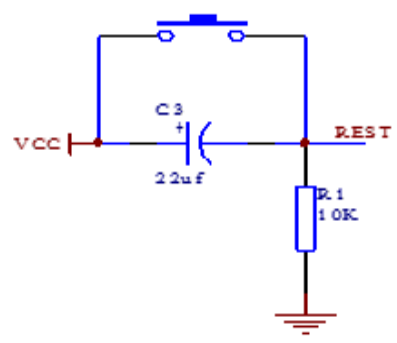

Figure 1 Power-on Button Reset Circuit

\section{Design of Temperature Measurement Circuit}

\subsection{Pin Diagram and Block Diagram of DS18B20}

The shape and pin pare to diagrams of DS18B20 is as shown in Figure 2.

(1)GND: ground signaling. (2)DQ: data input / output pin. When it is used under the parasite power, it can offer power to the components.(3)VDD: optional VDD pin. When it is operated under the parasite power, its pins must be grounded.

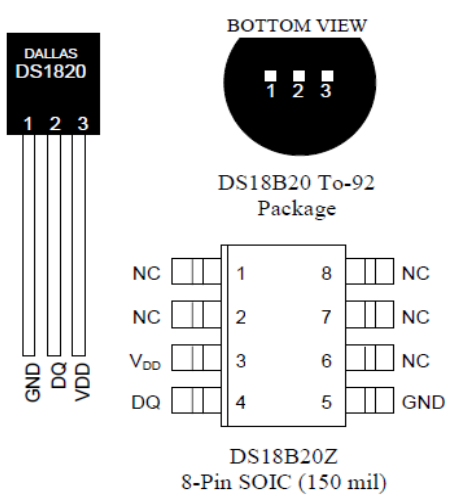

Figure 2 Shape and Pin Arrangement of DS18B20

\subsection{Buzzer Circuit}

The designed circuit is mainly composed of audion, buzzer, and resistance. The audion called Q1 functions as a switch. The high base electrical level makes the audition saturate and conduct, and the buzzer produce sound. Otherwise, the low base electrical level makes the audion close, and the buzzer produce sound, and the buzzer produce no sound. The buzzer circuit is as shown in Figure 3.

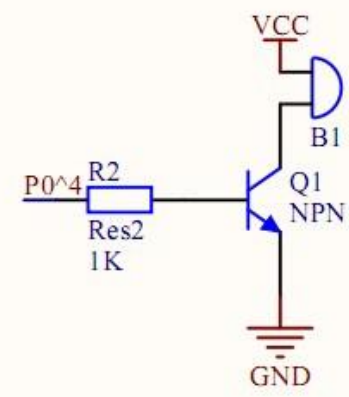

Figure 3 Buzzer Circuit 


\subsection{US-100 Ultrasonic Distance Measuring Module}

Method of application: a control port generates a high voltage level of 10US; the high voltage level can be output at the receiving nozzle. Once the high voltage level is output, the timer can be opened for timing. When the voltage level becomes low at the port, the value of the timer can be read. It is just the time of this distance measurement, and the distance can be calculated. The constant cycle measurement can attain the value of the mobile measurement.

\section{Summary}

This paper primarily introduces the overall design, hardware system design, and software system design and debugs method of the idea that the drinking fountain is controlled by the button. The optimal case should be selected with continuous design debug and improvement. The selected scheme has strong functions, high precision, good reliability, high stability, and strong anti-interference performance.

\section{Acknowledgements}

This work is supported the following fund: 2016 the project of improving the basic ability of young teachers in Colleges and universities in Guangxi: "Design and development of electronic commerce platform of agricultural products based on Semantic Technology" (No. KY2016YB455). 2015 college students' innovative training program: "Research on the application of value added travel experience in the mobile terminal of the 'ethnic custom travel' in Guangxi " (No 201511838070);\&\& "The design and development HeYuanTong Campus Mobile Phone APP based on Android " (No 201511838034).Project of scientific research and technology development project of Hezhou: "Design and implementation of agricultural products e-commerce platform based on Semantic Technology " (No, Hekeneng 1506006).

\section{References}

[1] B.Q LI, Y.F LING, H.Y ZHANG, and S.Y ZHENG: The Design and Realization of Cherry Tomato Harvesting Robot Based on IOT. International Journal of Online Engineering, 12(12), 23, (2016).

[2] B.Q LI, W.L GUAN, S.Y Zheng, X.G Yue: OPTIMISATION DESIGN OF CORN PRECISION SEEDER BASED ON MULTI-ROUTE AND MULTI-CHANNEL CONTROL. JOURNAL OF THE BALKAN TRIBOLOGICAL ASSOCIATION, 21(4A), 1215, (2015).

[3] Li Biqing, Zhu Qiang, Chen Ke Qing, Chen Ke Yin. Design of weed automatic recognition weeding robot based on embedded Web and ZigBee gateway. [J] Agricultural Mechanization Research.2017.1 (1)

[4] B.Q Li, et al, Intelligent Control Management System and Its Application, in: PROCEEDINGS OF THE 2016 INTERNATIONAL CONFERENCE ON ECONOMICS AND MANAGE MENT INNOVATIONS, Wuhan, China, 2016, PP.68-71.

[5] B.Q Li, et al, Design and Implementation of Tanks War Game Based on the Android Platform, in: PROCEEDINGS OF THE 2016 2ND WROKSHOP ON ADVANCED RESEARCH AND TECHNOLOGY IN INDUSTRY APPLICATIONS, Dalian, China, 2016, PP.963-966.

[6] B.Q Li, et al, Design of a Tea Garden Ant freezing Control System, in: PROCEEDINGS OF THE 2016 6TH INTERNATIONAL CONFERENCE ON MACHINERY, MATERIALS, ENVIRONMENT,BIOTECHNOLOGY AND COMPUTER(MMEBC), Tianjin, China, 2016, PP.736-738.

[7] B.Q Li, et al, Design of Electronic Compass, in: PROCEEDINGS OF THE 2016 6TH INTERNATIONAL CONFERENCE ON MACHINERY, MATERIALS, ENVIRONMENT, BIOTECHNOLOGY AND COMPUTER (MMEBC), Tianjin, China, 2016, PP.1240-1243. 
[8] B.Q Li, et al, Research of Automatically Light-Adjusting Lamp, in: PROCEEDINGS OF THE 2016 INTERNATIONAL CONFERENCE ON COMPUTER ENGINEERING, INFORM ATION SCIENCE \& APPLICATION TECHNOLOGY (ICCIA 2016), Guilin, China, 2016, PP.249-252.

[9] B.Q Li, et al, The Design and Realization of Fruit Harvesting Robot Based on IOT, in: PROCEEDINGS OF THE 2016 INTERNATIONAL CONFERENCE ON COMPUTER ENGINEERING,INFORMATION SCIENCE \& APPLICATION TECHNOLOGY (ICCIA 2016), Guilin, China, 2016, PP.261-264.

[10] B.Q Li, et al, A New Type of Automatic Opening and Closing Light-Operated Curtain, in: PROCEEDINGS OF THE 2016 INTERNATIONAL CONFERENCE ON MECHATRONICS ENGINEERING AND INFORMATION TECHNOLOGY(ICMEIT), Xian, China, 2016, PP.66-69.

[11] B.Q Li, et al, Design of the Intelligent Air Humidifier, in: PROCEEDINGS OF THE 2016 INTERNATIONAL CONFERENCE ON MECHATRONICS ENGINEERING AND INFORMATION TECHNOLOGY (ICMEIT), Xian, China, 2016, PP.201-203.

[12] B.Q Li, et al, The Design Implementation of the APP of Experiencing Guangxi Folk Custom, in: PROCEEDINGS OF THE 2016 INTERNATIONAL CONFERENCE ON ECONOMICS AND MANAGEMENT INNOVATIONS, Wuhan, China, 2016, PP.47-50.

[13] S.Y Zheng, et al, Digital Display Design of Ethnic Clothing of Nanling, in: PROCEEDINGS OF THE 4TH INTERNATIONAL CONFERENCE ON MECHATRONICS, MATERIALS. CHEMISTRY AND COMPUTER ENGINEERING 2015(ICMMCCE 2015), Xian, China, 2015, PP.2805-2808.

[14] S.Y Zheng, et al, Design and Implementation of Supermarket Personnel Management System Based On Java, in: PROCEEDINGS OF THE 2015 INTERNATIONAL CONFERENCE ON EDUCATION,MANAGEMENT AND COMPUTING TECHNOLOGY, Tianjin, China, 2015, PP.1724-1727.

[15] S.Y Zheng, et al, Analysis of Internet of Things Talent Training and Curriculum System Innovation, in: PROCEEDINGS OF THE 2016 INTERNATIONAL CONFERENCE ON EDUCATION,MANAGEMENT AND COMPUTING TECHNOLOGY(ICEMCT-16), Hangzhou, China, 2016, PP.957-960.

[16] S.Y Zheng, et al, Brief analysis on "HeYuanTong "Campus Mobile Phone APP Design, in: PROCEEDINGS OF THE 2015 5TH INTERNATIONAL CONFERENCE ON COMPUTER SCIENCES AND AUTOMATION ENGINEERING, Sanya, China, 2015, PP.151-154.

[17] S.Y Zheng, et al, Social Work in Teen Addiction Correction Services Research under the New Situation, in: PROCEEDINGS OF THE 2015 4TH NATIONAL CONFERENCE ON ELECTRICAL, ELECTRONICS AND COMPUTER ENGINEEERING (NCEECE 2015), Xian, China, 2015, PP.252-255. 